\title{
Hubungan Pengetahuan Ibu Hamil Trimester I dengan Kejadian Abortus di RSUD Arifin Achmad Pekanbaru
}

\section{The association of pregnant women trimester I knowledge with genesis abortion in RSUD Arifin Achmad Pekanbaru}

\section{Rita Afni}

\section{Prodi DIII Kebidanan STIKes Hang Tuah Pekanbaru}

\begin{abstract}
ABSTRAK
Abortus merupakan pengeluaran hasil konsepsi sebelum waktunya. Abortus dapat disebabkan karena pengetahuan ibu yang kurang. Penyebab AKI yang paling sering adalah perdarahan. Seperti yang telah diketahui sebelumnya bahwa perdarahan merupakan komplikasi dari terjadinya abortus. Ada banyak masalah kesehatan wanita khususnya pada kehamilan yang melatarbelakangi masalah atau komplikasi kehamilan serta menimbulkan kematian ibu, salah satunya adalah kejadian abortus. Data dari RSUD Arifin Achmad provinsi Riau kasus abortus tahun 2011 mencapai 94 orang ibu hamil, tahun 2012 kasus abortus menurun menjadi 90 kasus. Kemudian pada tahun 2013 sebanyak 109 orang. Tujuan penelitian ini adalah untuk mengetahui hubungan pengetahuan ibu hamil trimester Idengan kejadian abortus di RSUD Arifin Achmad Pekanbaru Tahun 2015. Metode penelitian ini menggunakan jenis penelitian analitik kuantitatif dan desain cross sectional. Penelitian ini diadakan di RSUD Arifin Achmad Provinsi Riau pada 4 April hingga 4 Mei tahun 2015. Populasi dalam penelitian ini adalah seluruh ibu hamil trimester I yang datang ke RSUD Arifin Achmad dan sampel diperoleh sebanyak 34 responden, dengan tekhnik sampling yaitu secara accidental sampling. Pengambilan data menggunakan data primer dengan menggunakan kuesioner, pengolahan data dilakukan dengan cara univariat dan bivariat. Hasil penelitian diperoleh mayoritas responden memiliki pengetahuan kurang sebanyak 28 orang $(82,4 \%)$ dan mengalami kejadian abortus sebanyak 21 orang $(61,8 \%)$. Sedangkan hasil uji chi square diperoleh hasil terdapat hubungan yang siginifikan antara pengetahuan dengan kejadian abortus dengan nilai $\mathrm{p}=0,007<0,05$. Diharapkan kepada tenaga kesehatan dapat meberikan informasi tentang faktor-faktor yang berhubungan dengan kejadian abortus kepada ibu hamil yang berkunjungan ke RSUD, agar ibu dapat mengetahuinya dan dapat melakukan pencegahan terhadap kejadian abortus
\end{abstract}

Kata Kunci : Pengetahuan, Kejadian Abortus, RSUD Arifin Achmad

\section{ABSTRACT}

Abortionis the result of conceptions pending prematurely. Abortion can be caused bylack of knowledge oftheir mother. The most frequent causes of maternal mortality are hemorrhage. As has been previously known that bleeding is a complication of abortion. There are many women's health issues, especially onthe background pregnancy problems or complications of pregnancy and thecauseof maternal mortality, one of whichisabortion. Data from Riau province Arifin Achmad abortion case in 2011 reached 94 pregnant women, abortion case in 2012 decreased to 90 cases. Then in the year 2013 as many as 109 people. The purpose of this study was to determine the relationship of knowledge of pregnant women with a first trimester abortion at Arifin Achmad Pekanbaru 2015.

This research methodusing aquantitative analytical research type and cross sectional Desaign. This research was conducted at Arifin Achmad Riau province on April 4 to May 4 2015. The population in this study were all first trimester pregnant women who cometo Arifin Achmad and obtaineda sample of 34 respondents, the sampling technique that is by accidental sampling. Retrieving data using primary data using questionnaires, data processing is computerized and data analysis done by univariate and bivariate. The results obtained by the majority of respondents have less knowledge as much as 28 people (82.4\%) and experienced abortion as many as 21 people $(61.8 \%)$. While the results of the chi square test results obtained significant correlation between knowledge with abortion with $p=0.007<0.05$. Expected to health workers cannot give information about the factors associated with the incidence of abortion to pregnant women who visit each other to hospitals, so that the mother can knowandbe able totake reasonable precautions against abortion.

Keywords : knowledge, genesis abortion, RSUD Arifin Achmad

\footnotetext{
${ }^{1}$ Alamat Korespondensi : Rita Afni, Email: afni_baex@yahoo.com
} 


\section{PENDAHULUAN}

Abortus merupakan berhentinya kehamilan sebelum usia kehamilan 20 minggu yang mengakibatkan kematian janin (Handono, dkk, 2009).

Menurut Badan Kesehatan Dunia (WHO) diperkirakan 4,2 juta abortus dilakukan setiap tahun di Asia Tenggara, dengan perincian 1,3 juta dilakukan di Vietnam dan Singapura, antara 750.000 sampai 1,5 juta di Indonesia, antara 155.000 sampai 750.000 di Filipina, antara 300.000 sampai 900.000 di Thailand (Septianingsih, 2009).

Angka Kematian Ibu (AKI) mengacu pada jumlah kematian ibu yang terkait dengan masa kehamilan, persalinan, dan nifas. Laporan Survei Demografi Kesehatan Indonesia (SDKI) tahun 2012, angka kematian ibu (AKI) tercatat mencapai 359 per 100 ribu kelahiran hidup. Kematian ini jauh melonjak dibanding hasil SDKI 2007 yang mencapai 228 per 100 ribu. Dalam hal ini, fakta lonjaknya kematian ini tentu sangat memalukan pemerintahan yang sebelumnya bertekad akan menurunkan AKI hingga 108 per 100 ribu pada 2015 sesuai dengan target MDGs (SDKI, 2007).

Penyebab AKI yang paling sering adalah perdarahan. Seperti yang telah diketahui sebelumnya bahwa perdarahan merupakan komplikasi dari terjadinya abortus. Ada banyak masalah kesehatan wanita khususnya pada kehamilan yang melatarbelakangi masalah atau komplikasi kehamilan serta menimbulkan kematian ibu, salah satunya adalah kejadian abortus (Septianingsih, 2009).

Di Indonesia frekuensi abortus sukar ditentukan karena abortus buatan banyak tidak dilaporkan, kecuali apabila terjadi komplikasi; juga disertai karena sebagian abortus spontan hanya disertai gejala ringan, sehingga pertolongan medic tidak diperlukan dan kejadian ini dianggap sebagai haid terlambat, dan diperkirakan frekuensia abortus spontan berkisar $10-15 \%$ (Kusmiaty, dkk, 2009).

Ada beberapa faktor yang merupakan predisposisi terjadinya abortus salah satunya adalah pengetahuan ibu yang kurang. Pada dasarnya abortus dapat dicegah dengan cara mengenali tanda-tanda bahaya selama kehamilan. Secara teoritis terdapat beberapa tanda bahaya pada masa kehamilan khususnya kehamilan muda yang meliputi; perdarahan yang timbul hanya berupa bercak atau perdarahan yang banyak dan disertai dengan rasa sakit dibagian perut (Kusmiaty, dkk, 2009).
Tanda bahaya pada kehamilan merupakan tanda gejala yang menunjukkan ibu atau bayi yang dikandungnnya dalam keadaan bahaya. Bila ada tanda bahaya, biasanya ibu perlu mendapat pertolongan segera di rumah sakit (hospital emergency). Kebanyakan kehamilan berakhir dengan persalinan dan masa nifas yang normal. Namun 15 sampai 20 diantara 100 ibu hamil mengalami gangguan pada kehamilan, persalinan atau nifas. Gangguan tersebut dapat terjadi secara mendadak, dan biasanya tidak dapat diperkirakan sebelumnya (unpredictable disruption). Karena itu, tiap ibu hamil, keluarga dan masyarakat perlu mengetahui dan mengenali tanda bahaya. Tujuannya, agar dapat segera mencari pertolongan ke bidan, dokter, atau langsung ke rumah sakit, untuk menyelamatkan jiwa ibu dan bayi yang dikandungnya (Laily, 2011).

Berdasarkan data dari RSUD Arifin Achmad provinsi Riau kasus abortus tahun 2011 mencapai $23 \%$ ibu hamil yang berkunjung, tahun 2012 kasus abortus menurun menjadi 20\%. Kemudian pada tahun 2013, kasus abortus menjadi kasus nomor 2 yang terbesar dari 10 kasus yang ada dalam kebidanan yaitu sebanyak $37 \%$. Dari survey awal yang dilakukan peneliti terhadap 10 orang ibu hamil trimester pertama diperoleh hasil sebanyak 8 orang tidak mengetahui tentang abortus yang meliputi pengertian, tanda dan gejala, penyebab dan lainnya. Selain dari pada itu, 2 orang diantaranya mengaku mengalami perdarahan yang hanya bercak pada kehamilannya. Hal ini menggambarkan ibu tersebut berisiko mengalami abortus.

Berdasarkan latarbelakang diatas peneliti ingin melakukan penelitian yang bertujuan untuk mengetahui hubungan pengetahuan ibu hamil trimester I dengan kejadian abortus di RSUD Arifin Achmad Pekanbaru Tahun 2015.

\section{METODE PENELITIAN}

Metode penelitian ini menggunakan jenis penelitian analitik kuantitatif dengan desain cross sectional. Penelitian ini diadakan di RSUD Arifin Achmad Provinsi Riau pada 4 April hingga 4 Mei tahun 2015. Populasi dalam penelitian ini adalah seluruh ibu hamil trimester I yang datang ke RSUD Arifin Achmad dan sampel diperoleh sebanyak 34 responden, dengan teknik sampling yaitu secara accidental sampling. Pengambilan data menggunakan data primer dengan 
menggunakan kuesioner yang berisi tentang tanda bahaya kehamilan yang berjumlah 25 pertanyaan yang telah dilakukan uji validitas dan releabilitas sebelumnya, kemudian kuesioner dibagikan kepada responden. Pengolahan data dilakukan dengan cara univariat dan bivariat.

\section{HASIL}

Dari hasil penelitian yang telah dilakukan, diperoleh hasil dan pembahasan tentang hubungan pengetahuan ibu hamil trimester I tentang tanda bahaya kehamilan dengan kejadian abortus di RSUD Arifin Achmad Pekanbaru Tahun 2015 yang dilaksanakan pada tanggal 4 April hingga 4
Mei tahun 2015 yang didapatkan dari 34 orang responden diketahui bahwa karakteristik responden sebagian besar responden berumur 20-35 tahun sebanyak 18 orang $(52,8 \%)$, sebagian besar responden berpendidikan rendah sebanyak 29 orang $(85,3 \%)$, sebagian besar responden tidak bekerja sebanyak 31 orang $(91,2 \%)$ dan sebagian besar responden kehamilan multiparitas sebanyak 19 orang $(55,9 \%)$.

\section{Analisa Bivariat}

Hasil penelitian didapatkan bahwa ada hubungan antara pengetahuan ibu hamil trimester I tentang tanda bahaya kehamilan dengan kejadian abortus dengan $\mathrm{p}$ value $(0,007)$.

\section{Hubungan Pengetahuan Ibu Hamil Trimester I Tentang Tanda Bahaya Kehamilan Dengan Kejadian Abortus Di RSUD Arifin Achmad Provinsi Riau}

Tahun 2015

\begin{tabular}{cccccccc}
\hline Pengetahuan & \multicolumn{3}{c}{ Abortus } & $\mathbf{( \% )}$ & Total & $\mathbf{( \% )}$ & $\begin{array}{c}\text { P } \\
\text { value }\end{array}$ \\
\cline { 2 - 7 } & Abortus & $\mathbf{\%}$ & Tidak & & & & 0,007 \\
\hline Kurang & 21 & 75,0 & 7 & 25,0 & 28 & 100 & \\
\hline Baik & 2 & 33,3 & 4 & 66,7 & 6 & 100 & \\
\hline Total & 23 & 67,6 & 11 & 26,4 & 34 & 100 & \\
\hline
\end{tabular}

\section{PEMBAHASAN}

Berdasarkan hasil uji chi square diperoleh $\mathrm{P}_{\text {value }}$ yaitu $0,007<0,05$ artinya bahwa terdapat hubungan antara pengetahuan ibu hamil trimester I tentang tanda bahaya kehamilan dengan kejadian abortus.

Tanda bahaya pada kehamilan merupakan tanda gejala yang menunjukkan ibu atau bayi yang dikandungnnya dalam keadaan bahaya. Bila ada tanda bahaya, biasanya ibu perlu mendapat pertolongan segera di rumah sakit (hospital emergency).

Kebanyakan kehamilan berakhir dengan persalinan dan masa nifas yang normal. Namun 15 sampai 20 diantara 100 ibu hamil mengalami gangguan pada kehamilan, persalinan atau nifas. Gangguan tersebut dapat terjadi secara mendadak, dan biasanya tidak dapat diperkirakan sebelumnya (unpredictable disruption). Karena itu, tiap ibu hamil, keluarga dan masyarakat perlu mengetahui dan mengenali tanda bahaya. Tujuannya, agar dapat segera mencari pertolongan ke bidan, dokter, atau langsung ke rumah sakit, untuk menyelamatkan jiwa ibu dan bayi yang dikandungnya (Laily, 2011).

Ada beberapa faktor yang merupakan predisposisiterjadinyaabortussalah satunya adalah pengetahuan ibu yang kurang dalam mengenali tanda bahaya kehamilan. Pada dasarnya abortus dapat dicegah dengan cara mengenali tanda-tanda bahaya selama kehamilan. Secara teoritis terdapat beberapa tanda bahaya pada masa kehamilan khususnya kehamilan muda yang meliputi; perdarahan yang timbul hanya berupa bercak atau perdarahan yang banyak dan disertai dengan rasa sakit dibagian perut (Kusmiaty, dkk, 2009).

Pengetahuan merupakan hasil dari tahu yang diperoleh dari penginderaan (Notoatmodjo (2014). Menurut Adji (2004), salah satu factor yang mempengaruhi pengetahuan adalah informasi. Informasi dapat diperoleh dari berbagai media baik media cetak maupun media elektronik. Mendapatkan informasi adalah hak setiap manusia, tergantung dari minat dan kesadaran akan kebutuhan dari mereka. Informasi sangat penting bagi kehidupan manusia, semakin banyak seseorang mendapatkan informasi maka semakin baik pengetahuan yang dimilikinya, dan sebaliknya semakin jarang manusia mendapatkan informasi maka semakin kurang pengetahuannya.

Hal ini sejalan dengan penelitian Ertina (2011), yang bertujuan mengetahui hubungan pengetahuan dan sikap ibu hamil tentang kejadian abortus di RS Mitra Husada Medan, diperoleh hasil uji statistik dengan chi square $p_{\text {value }}=0,002<0,05$, artinya terdapat hubungan antara pengetahuan dengan kejadian abortus.

Menurut penelitian Ardina (2009), yang bertujuan mengetahui faktor-faktor yang berhubungan dengan kejadian abortus di RS Bina Kasih, diperoleh hasil uji statistik dengan chi square $p_{\text {value }}=0,094<$ 0,05 , artinya tidak terdapat hubungan antara pengetahuan dengan kejadian abortus. Tidak adanya hubungan ini dilatar belakangi oleh karena sebagian besar responden sudah mengetahui tentang tanda dan gejala abortus, akan tetapi faktor lain seperti terjadinya 
trauma atau kecelakaan yang tidak bisa dihindarkan mengakibatkan ibu mengalami abortus.

Berdasarkan hasil penelitian dan teori diatas, peneliti berasumsi bahwa ibu yang memliki pengetahuan kurang dapat mengakibatkan kejadian abortus. Hal ini disebabkan karena ibu tidak pernah mendapatkan informasi tentang tanda bahaya pada masa kehamulan, sehingga ibu tidak tahu bagaimana cara mengenali tanda bahaya kehamilan yang berujung pada kejadian abortus. Akan tetapi dari hasil penelitian terdapat 3 orang responden yang berpengetahuan baik dan mengalami abortus hal ini disebabkan oleh karena responden mengalami kecelakaan, hal ini diperoleh dari pengamatan yang dilakukan oleh peneliti dilapangan bahwa terdapat 3 orang ibu hamil mengatakan terjatuh dari motor, terpeleset dikamar mandi dan 1 orang ibu memiliki penyakit kandungan dan sering mengalamiabortus sebelumnya.

\section{KESIMPULAN}

Sebagian besar responden berpengetahuan kurang sebanyak 28 orang $(82,4 \%)$ dan terdapat hubungan yang siginifikan antara hubungan antara pengetahuan dengan kejadian abortus dengan nilai $\mathrm{p}=$ $0,007<0,05$.

\section{SARAN}

Diharapkan kepada tenaga kesehatan dapat meberikan informasi tentang faktor-faktor yang berhubungan dengan kejadian abortus kepada ibu hamil yang berkunjungan ke RSUD, agar ibu dapat mengetahuinya dan dapat melakukan pencegahan terhadap kejadian abortus.

\section{UCAPAN TERIMA KASIH}

Ucapan terima kasih ditujukan kepada Ketua STIKes dan Ketua Prodi Kebidanan STIKes Hang Tuah Pekanbaru yang selalu memberikan dukungan dan semangat.

\section{DAFTAR PUSTAKA}

Asrul, 2009. Perilaku Kesehatan. Jakarta : Nusantara.

Ardina (2009), Faktor-Faktor Yang Berhubungan Dengan Kejadian Abortus Di RS Bina Kasih

Ertina, 2011, Hubungan Pengetahuan Dan Sikap Ibu Hamil Tentang Kejadian Abortus Di RS Mitra Husada Medan.

Hidayat, A. A. 2007. Metode Penelitian Kebidanan dan Teknik Analisis Data. Jakarta : Salemba Medika

Hikmawati, 2012. Promosi Kesehatan Untuk Kebidanan. Jogyakarta : Nuha Medika

Kusmiaty, dkk, 2009. Buku Ajar AsuhanKebidananPadaIbuNifas.Jakarta Andi Offset.

Lailay, 2008. Kesehatan ReproduksiWanita, http://www.ypkp.net/. Diakses 14 Januari 2015

Manuaba, dkk, 2006.Memahami Kesehatan Reproduksi Wanita.Jakarta : ECG

Riwidikdo, 2008.StatistikKesehatan.Jakarta :Bumi Perkasa

Setiawan\& Saryono, 2011.MetodologiPenelitianKebidanan DIII, $D I V, S 1$, dan S2. Yogyakarta: Nuha Medika.

Setiawan\&Saryono, 2010.MetodelogiPenelitianKebidanan DIII, DIV, S1 dan S2. Yogyakarta :MuliaMedika

SDKI, 2007. Peranan MDGS BagiKesehatanDunia.www.medicastor//peranan /mdgs/bagi/kesehatan/dunia.12-11-010. diakses 11Januari 2015

Septianingsih. D. 2009. AsuhanKehamilan.Jakarta :NuhaMedika

Setiawan\&Saryono 2010.Metodelogipenelitiankebidanan DIII, DIV, S1 dan S2.Yogyakarta: MuliaMedika.

Wahyuni, 2010. Dasar-Dasar Statistik Deskriptif. Jakarta : Nuha Medik. 